\title{
Preparation Process, Sensory Profile and Chemical Composition of
}

\section{Sargyangma - A Traditional Food of Limbu Community}

\author{
PREM KUMAR LIMBU, DEVRAJ ACHARYA and DILIP SUBBA
}

Central Campus of Technology, Hattisar, Dharan, Nepal

\begin{abstract}
The aim of present work was to describe the traditional process of preparation, sensory profile and chemical composition of Sargyangma. Sargyangma was prepared in lab and its descriptive sensory test and chemical analysis were performed. The colour of Sargyangma was slightly brown and unevenly distributed. Sargyangma had characteristic aroma and taste mainly due to cooked blood and Yangben. Yangben is local word used by Limbu ethnic community for edible lichen. This had moderately intense bloody aroma and taste. Very intense Yangben aroma and taste was readily detectable. In the overall, Sargyangma had moderately intense pleasant, porky-meaty, spicy aroma. Sargyangma was found to be compact and juicy containing high amount of fat (29.2\%) and moderate amount of protein (13.33\%).
\end{abstract}

Key words: Chemical composition, Preparation process, Sargyangma, Sensory profile

\section{Introduction}

Nepal is notable for its diverse food culture. A wide variety of indigenous foods are prepared by different ethnic communities of Nepal (Subba, 2012). Sargyangma is an indigenous sausage product named and made by Limbu ethnic people of Nepal living in Eastern mountain region of the country. It is popular in Limbu community. Sargyangma is normally prepared during festive and cultural occasions rather than being a commercial product. Limbu people have tradition of raising pig in house backyard. When a family slaughters pig they offer it to god before the family consumes its meat. During such occasions of house slaughtering of pig its meat, blood and organs are used for preparing a type of sausage called Sargyangma. The regularly used ingredients for preparing Sargyangma are pork belly, blood, liver, heart, killing fats and Yangben. Yangben is local word used by Limbu ethnic community for edible lichen (Bhattarai et al., 1999). Yangben is indispensable flavouring ingredient used in Sargyangma. Yangben is traditionally processed and preserved by cooking in ash water, washing and drying. Occasionally rice, vegetables, pig head meat and lean meat also be used. The meat, fat and organs are coarsely chopped by Khukuri (a local word used for heavy knife) on wooden chopping block and mixed with blood, Yangben, salt and spices. The mixture is stuffed in a cleaned hog large intestine (middle) and cooked properly. The information on technology of Sargyangma is too general, in form of personal communication and imprecise. To date, only one publication, a book by Kharel et al. (2010) contains introductory information on this product. The aim of this work was to describe the traditional process of preparation and sensory profile of Sargyangma and determine its chemical composition.

Materials and Methods
Traditional knowledge was used as basis for the preparation of Sargyangma. Random qualitative survey was conducted in East mountain region of Nepal to gather information on ingredients, their proportions and process of preparation of Sargyangma. The subjects involved were the households and individuals (total 52) who either knew to prepare Sargyangma or had some knowledge about it. Most commonly used recipe and process of preparation was taken as reference to reproduce Sargyangma in lab. Pork belly, leaf fat, blood, liver, heart and large intestine were brought from the local market. Belly was skinned and cut into small pieces. Likewise, heart, liver and fat were cut into small pieces. The pieces of meat, fat and organs were mixed and ground coarsely by passing through a $5 \mathrm{~mm}$ grinder plate of kitchen meat grinder. Dry Yangben obtained from local market was soaked in water and cut into fine pieces. The grinded meat and by-product was mixed properly with blood, Yangben, salt and finely ground fresh ginger and garlic. The proportions of different ingredients were belly 50 , blood 20 , fat 5 , liver 15 , heart 10 to make 100 parts by weight of the mixture. Yangben and table salt were added at the rate of $5 \mathrm{~g}$ and $2 \mathrm{~g}$ per $100 \mathrm{~g}$ of the mixture respectively. The spices were added in quantities sufficient to give taste. The sausage batter was filled in properly cleaned pig large intestine and tied at $15 \mathrm{~cm}$ length intervals. This was cooked in hot water $\left(85^{\circ} \mathrm{C}\right)$ for $45 \mathrm{~min}$. Core temperature of the Sargayangma recorded was $75^{\circ} \mathrm{C}$. The product was then cooled in water.

The sensory analysis of Sargyangma was performed as per the principle and procedure of Spectrum ${ }^{\mathrm{TM}}$ Descriptive Analysis Method developed by Civille (1979). For this at first, orientation training was organized for sensory test panel so to make the panelists familiar with terminology used in the sensory analysis. The training involved 8 senior students of food technology and the training was conducted for four consecutive days. A lexicon similar in style of 
Johnsen and Civille (1986) comprising all terms used for sensory analysis of Sargyangma as shown in Table 1 was developed.

Table 1 Lexicon for descriptive sensory analysis of Sargayangma

Terms used for sensory attributes Description

Aroma

Overall aroma

Aroma associated with a typical sausage aroma that is pleasant, porky, spicy and meaty.

Bloody aroma

Aromatics associated with cooked pork blood, could be present but not overpowering (not too intense).

Offal aroma

Aromatics associated with cooked offal such as a mixture of pork heart, liver, and intestines. Could be present but not too overpowering or intense.

Yangben aroma

Aromatics associated with a typical strong aroma of Yangben.

Taste

Overall taste

Typical sausage taste

Bloody taste

A blood taste that is readily detectable part of the overall taste of the Sargyangma but it should not be too intense.

Offal taste

Taste associated with cooked offal such as a mixture of pork heart, liver, and intestines.

Yangben taste

Typical Yangben taste that is readily detectale part of the overall taste of the

Sargyangma.

\section{Texture}

Consistency

The consistency refers to the product cohesiveness as how much does it hold together or break up when beginning to bite, shear and chew.

Pasty - smooth but sticking to top of mouth

Compact - firm or solid, sticks together.

Toughness and chewiness

The amount of energy and number of chewing required before swallowing.

If it is soft and mushy, it is easy to swallow. If it is tough and chewy it requires a lot of energy to shear and chew it.

Juiciness

Perception of wetness in palate and mouth as impressed by water and fat/oil

The sausage was cut in $5 \mathrm{~mm}$ thin slices and presented in warm condition to the panelists.

Eight-point descriptive rating test (Table 2) was used to rate the sensory attributes colour, aroma, taste and texture, where 1 represented extremely weak intensity and 8 represented extremely strong intensity (Table 2). The panelists were asked to assign the most justified point in the rating scale. Chemical composition of fresh Sargyangma was determined (three determinations) according to AOAC (2005).

Table 2 Sensory rating scale for descriptive rating test

Colour

8 Extremely dark brown and evenly distributed 
7 Very dark brown and evenly distributed 6 Moderately dark brown and evenly distributed 5 Slightly brown and unevenly distributed 4 Brownish and unevenly distributed 3 Moderately light and unevenly distributed 2 Very light and unevenly distributed

1 Extremely light and unevenly distributed

Aroma

\begin{tabular}{|c|c|c|}
\hline overall aroma & bloody aroma & offal aroma \\
\hline 8 Extremely intense & 8 Extremely intense & 8 Extremely $\mathrm{i}$ \\
\hline 7 Very intense & 7 Very intense & 7 Very intens \\
\hline 6 Moderately intense & 6 Moderately intense & 6 Moderately \\
\hline 5 Slightly intense & 5 Slightly intense & 5 Slightly int \\
\hline 4 Slightly bland & 4 Slightly bland & 4 Slightly bla \\
\hline 3 Moderately bland & 3 Moderately bland & 3 Moderately \\
\hline 2 Very bland & 2 Very bland & 2 Very bland \\
\hline 1 Extremely bland & 1 Extremely bland & 1 Extremely b \\
\hline \multicolumn{3}{|l|}{ Taste } \\
\hline overall taste & bloody taste & yangb \\
\hline 8 Extremely intense & 8 Extremely intense & 8 Extr \\
\hline 7 Very intense & 7 Very intense & 7 Very \\
\hline 6 Moderately intense & 6 Moderately intense & $6 \mathrm{Mod}$ \\
\hline 5 Slightly intense & 5 Slightly intense & 5 Slig \\
\hline 4 Slightly bland & 4 Slightly bland & 4 Slig \\
\hline 3 Moderately bland & 3 Moderately bland & $3 \mathrm{Mod}$ \\
\hline 2 Very bland & 2 Very bland & 2 Very \\
\hline 1 Extremely bland & 1 Extremely bland & 1 Extr \\
\hline
\end{tabular}

Texture

Toughness, Chewiness

8 Extremely tough and chewy

7 Very tough and chewy

6 Moderately tough and chewy
5 Slightly tough and chewy

5 Slightly compact

4 Slightly soft and mushy

4 Slightly pasty

3 Moderately soft and mushy

3 Moderately pasty

2 Very soft and mushy

2 Very pasty

1 Extremely soft and mushy

1 Extremely pasty

\section{Results and discussion}

All communities have their traditional foods. Many of them have been well studied and documented and many of the traditional processes have be exn industrializend (Anon., 1992; Steinkraus, 1996; Steinkraus, 2014; Tamang, 2010). Scientific enquiries are essevtial iffenßeserving traditional knowledge and one's intellectual property. Preparing Bregsengma is further way6tMbderzathy tinteonsally important asfective to alleviate prob\$eShighflynialtemtration in affected communities. Sargyangma has simple technology and it is a nifow price food product. 4 Slightly bland

The mean panel score for sensory quality of Sargyangma bland 1 ) is given in Table 3 . Moderately bland 
The colour of Sargyangma was slightly brown and unevenly distributed. The lightness of colour and unevenness in colour was due to presence and distribution of fat. The brown shade of colour could be due to the appearance of cooked blood and liver. Sargyangma had characteristic aroma and taste mainly associated to cooked blood and Yangben. This had slightly intense bloody aroma and moderately intense blood taste. Very intense yangben aroma and taste was readily detectable in Sargyangma. Sargyangma smelled slightly after offal due to cooked liver, heart and intestine used as casing. In the overall, Sargyangma had moderately intense Attributes

Mean \pm SD

$3.95 \pm 0.75$

Aroma

Overall sausage aroma

$6.1 \pm 0.64$

bloody aroma

$5.65 \pm 0.74$

offal aroma

$5.35 \pm 0.67$

yangben aroma

$6.85 \pm 0.59$

Taste

Overall taste

$6.1 \pm 0.64$

Bloody taste

$6.25 \pm 0.55$

Offal taste

$5.2 \pm 0.69$

Yangben taste

$6.9 \pm 0.64$ pleasant, porky-meaty, spicy aroma. The texture of Sargyangma was considered to be slightly tough and chewy. The impression of toughness and chewiness was due to middle as casing. The consistency of Sargyangma was moderately compact, material held well together. The sausage was moderately juicy due to high moisture and moderate fat content.

Table 3 Sensory evaluation of Sargyangma

Texture

Chewiness

Consistency

$5.75 \pm 0.44$

Juiciness

$6.2 \pm 0.61$ 
Table 4 Chemical composition of Sargyangma

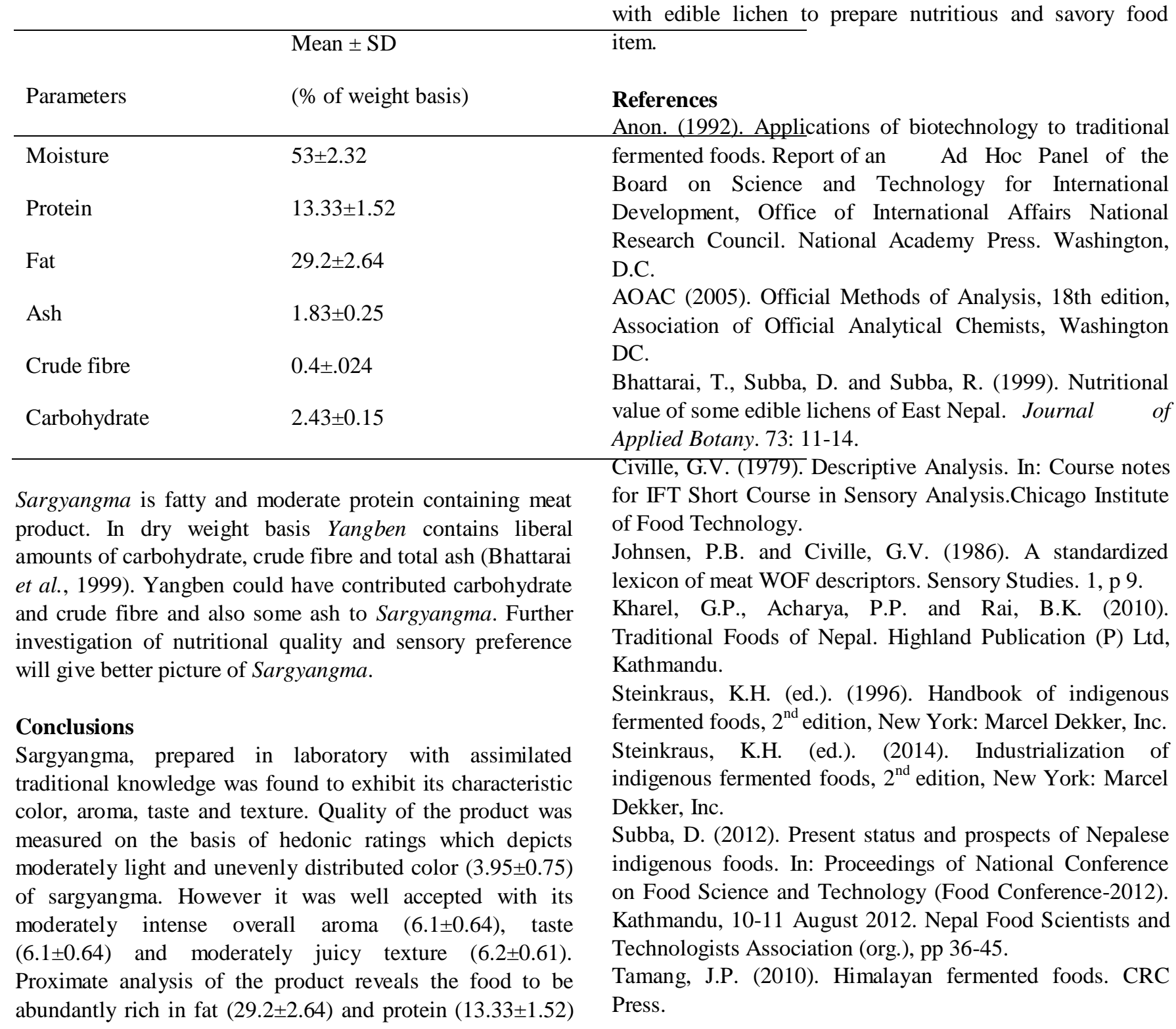

nutrients. Thus, by products like organs, offals could be used with edible lichen to prepare nutritious and savory food

\section{References}

Anon. (1992). Applications of biotechnology to traditional fermented foods. Report of an Ad Hoc Panel of the Board on Science and Technology for International Development, Office of International Affairs National Research Council. National Academy Press. Washington, AOAC (2005). Official Methods of Analysis, 18th edition, Association of Official Analytical Chemists, Washington DC.

Bhattarai, T., Subba, D. and Subba, R. (1999). Nutritional value of some edible lichens of East Nepal. Journal of Applied Botany. 73: 11-14

for IFT Short Course in Sensory Analysis.Chicago Institute

lexicon of meat WOF descriptors. Sensory Studies. 1, p 9.

Kharel, G.P., Acharya, P.P. and Rai, B.K. (2010). Traditional Foods of Nepal. Highland Publication (P) Ltd, Kathmandu.

Steinkraus, K.H. (ed.). (1996). Handbook of indigenous fermented foods, $2^{\text {nd }}$ edition, New York: Marcel Dekker, Inc. Steinkraus, K.H. (ed.). (2014). Industrialization of indigenous fermented foods, $2^{\text {nd }}$ edition, New York: Marcel Dekker, Inc.

Subba, D. (2012). Present status and prospects of Nepalese indigenous foods. In: Proceedings of National Conference on Food Science and Technology (Food Conference-2012). Kathmandu, 10-11 August 2012. Nepal Food Scientists and Technologists Association (org.), pp 36-45.

Tamang, J.P. (2010). Himalayan fermented foods. CRC of Food Technology. 